\title{
Genital flaps for anterior urethral reconstruction
}

\author{
Nathan M. Shaw, Gregory Amend, Benjamin N. Breyer \\ Department of Urology, University of California, San Francisco, CA 94110, USA. \\ Correspondence to: Prof. Benjamin N. Breyer, Department of Urology, University of California, Box 0807, Floor 10, Room 20, \\ 1001 Potrero Ave, San Francisco, CA 94110, USA. E-mail: benjamin.breyer@ucsf.edu \\ How to cite this article: Shaw NM, Amend G, Breyer BN. Genital flaps for anterior urethral reconstruction. Plast Aesthet Res \\ 2021;8:52. https://dx.doi.org/10.20517/2347-9264.2021.53
}

Received: 27 May 2021 First Decision: 26 Jul 2021 Revised: 27 Jul 2021 Accepted: 9 Aug 2021 Published: 17 Sep 2021

Academic Editors: Miroslav L. Djordjevic, Stan M. Monstrey Copy Editor: Xi-Jun Chen Production Editor: Xi-Jun Chen

\begin{abstract}
Genital flaps can provide versatile options for complex penile, genital, and urethral reconstruction. Pedicled muscle flaps can be used in combination with grafting for urethral reconstruction, and genital skin flaps can also be utilized as urethral augmentation or replacement. Penile skin flaps, in particular, offer versatile options for the management of anterior urethral stricture disease. The choice of urethral reconstruction depends on surgeon expertise and patient disease. Given its surgical complexity, flap reconstruction is equally dependent on an appropriate understanding of patient disease and surgeon experience. It is crucial to understand the patients' comorbid diseases (e.g., smoking status or lichen sclerosis), potential flap tissue quality (i.e., penile/preputial skin quality), and stricture anatomy (length, caliber, location). Of particular importance is any prior intervention that may alter the normal vascular supply to the proposed flap. The ideal skin flap will be (1) hairless; (2) accustomed to the aqueous environment; (3) adaptable; and (4) cosmetic. This review will cover the operative approaches and perioperative outcomes of genital flaps to manage urethral reconstruction. Particular attention will be paid to penile skin flap urethroplasty.
\end{abstract}

Keywords: Urethral stricture, genital flap, penile flap, reconstructive urology

\section{INTRODUCTION}

Urethroplasty is the gold standard for the treatment of urethral stricture disease. While urethroplasty techniques can be technically demanding and have a significantly associated learning curve, the success rates are excellent and significantly better than endoscopic alternatives ${ }^{[1]}$. Urethral grafting, genital skin 
flaps, and combined tissue transfer provide durable options for single or two-stage repairs. However, there is no consensus on a single best reconstructive technique as the efficacy of each technique in restoring urethral patency varies with both patient disease and surgeon expertise ${ }^{[2,3]}$.

Anterior and posterior urethral strictures are considered separate disease processes, and flaps do not currently play a role in posterior urethral reconstruction. Therefore, this review will focus on the use of genital skin flaps, particularly those derived from penile skin, in anterior urethral reconstruction. Special consideration should be taken for cases of urethral reconstruction in patients with a neophallus. Urethral reconstruction in these patients is inherently complicated as the vascular supply of the neophallus is derived from a non-anatomic pedicled flap. The description of penile skin flaps is therefore not applicable in the reconstruction of the urethra in the neophallus as penile skin flaps depend on native penile vasculature. For the purposes of this review, the focus will be on male anterior urethral stricture disease with native penile tissue. Patient selection, flap characteristics, focused genital anatomy, and types of flaps will be discussed. Operative approaches and recommendations on the use of each flap will be provided in addition to an overview of published success rates.

\section{PATIENT SELECTION}

Appropriate understanding of patient comorbid diseases is essential in the choice of urethral reconstruction. The approach to genital flaps, in particular, can be surgically challenging, and appropriate patient selection is crucial. Patient comorbid diseases, particularly conditions that can compromise blood flow, are important to understand as they can affect flap failure and wound healing. For example, patients with a history of smoking, peripheral vascular disease, or radiation are at a higher rate of flap failure ${ }^{[4]}$. Physical examination to assess penile/genital skin integrity and concomitant wounds, fistulae, or abscesses is also important to select appropriate flap locations and counsel patients on post-operative expectations. The presence of lichen sclerosis (LS) bears particular mention. While there are reports of using flaps from uninvolved genital skin in patients with LS, the success rates are lower, and often a two-stage approach has been preferred in this population $^{[5-7]}$. Therefore, skin involved with LS should not be used for urethral reconstruction.

Stricture location and length often indicate the surgical technique best suited for repair. Genital flaps with or without combined tissue transfer can play a role in bulbar urethroplasty, but generally, anastomotic or buccal mucosal grafting (BMG) is preferred in the bulbar urethra. The tunneling of penile skin into the perineum adds additional technical challenges - which makes this technique less favorable given the durable success rates of $\mathrm{BMG}^{[8-12]}$. In general, flaps have fallen out of favor as a mainstream reconstructive option in favor of BMG due to the risk of flap loss, increased technical demands, and patient satisfaction ${ }^{[13,14]}$. In the appropriately selected patient, however, flaps still offer excellent success. Obliterative strictures can be particularly challenging to manage as these have the insufficient dorsal urethral plate to perform onlay techniques. For short obliterative strictures $(<2 \mathrm{~cm})$, particularly in the bulbar urethra, anastomotic urethroplasty with excision of the obliterated urethra is preferred due to the high published success rate. For longer obliterative strictures, the dorsal urethral plate requires reconstruction. Combined tissue transfer with dorsal graft (e.g., BMG) and ventral skin flap can be used in these cases. Two-stage repair, where the first stage reconstructs the dorsal plate, can also be considered. Tubularized repairs are not preferred and should be avoided if possible.

Patient age and goals are also important for patient counseling and choosing the appropriate reconstructive technique. For older men with significant comorbidities, operations with less time in lithotomy position or highest single-stage success may be preferred to the durability of repair. Paramount to this discussion is an understanding of patients' sexual function. There is emerging evidence that non-transecting techniques may 
preserve sexual function and may be favored in patients of younger age $\mathrm{e}^{[15]}$. In addition, de novo persistent erectile dysfunction is rare following anterior urethroplasty $(\sim 1 \%)^{[16]}$.

\section{Flap characteristics}

There are four primary factors that characterize the ideal flap. Flaps should be (1) hairless; (2) accustomed to the aqueous environment; (3) adaptable; and (4) $\operatorname{cosmetic}^{[17]}$. Each factor will be discussed briefly, with more depth provided in the discussion of individual flaps.

\section{Hairless}

Flaps should be derived from non-hair bearing skin. Hair in chronic contact with urine will lead to bacterial urethral colonization, stone formation, and inflammation. Accordingly, penile prepuce and distal penile shaft skin are preferred over the proximal penile shaft and scrotal skin.

\section{Aqueous environment}

Choice of urethral augmentation should preferentially favor tissue that is accustomed to or adaptable to the aqueous environment. Skin not accustomed to this environment will become inflamed and will be prone to squamous metaplasia. Chronic inflammation and metaplastic changes are concerning for both stricture recurrence and malignant transformation. This includes skin that is already diseased with active inflammatory processes (e.g., LS).

\section{Adaptable}

Ideal flaps should provide adequate urethral caliber in varying locations and be mobile enough to treat strictures in variable locations in the urethra. This includes skip lesion strictures. While non-hair bearing skin can be found elsewhere in the groin, none is as adaptable as penile skin.

\section{Cosmesis}

The creation of suture lines that approximate anatomic skin markings is an important consideration in the choice of the flap. Concomitant skin conditions such as vitiligo should also be considered for the choice of flap location. Additionally, the possibility of debilitating another structure is another consideration for flaps, particularly for use in tissue transfer.

\section{SCROTAL AND GENITAL ROTATION FLAPS}

Scrotal and various rotational flaps (e.g., anterior thigh) were popularized prior to the wide use of penile skin flaps and BMG. Now primarily of historical importance, these flaps tend to fail to meet one or more of the four factors necessary for flap success. Scrotal flaps were widely used at one point, but the incorporation of hair-bearing skin into the urethra leads to unacceptable long-term outcomes with stones and infections ${ }^{[18-24]}$. Other flaps, including the incorporation of thigh skin which may not be hair-bearing, had comparatively short pedicles and were not appropriate in the reconstruction of the penile urethra. With rare exceptions, these skin flaps have been abandoned for use as the urethral replacement.

The use of non-skin pedicled rotational flaps (i.e., gracilis) as an interposition layer for fistula reconstruction and in combination with grafting continues to be actively used and investigated ${ }^{[25]}$. For example, rotational gracilis flaps have been combined with BMG to manage complex bulbar strictures ${ }^{[26]}$. A full discussion of these cases is outside the scope of this review. 


\section{Penile skin flaps}

Penile skin flaps can provide single-stage reconstruction, even in long-segment anterior urethral stricture disease. Penile skin, particularly distal or preputial skin, in the appropriately selected patient will meet the four primary factors for an ideal flap. These flaps share a common blood supply from the external pudendal artery and involve the isolation of a skin island that is mobilized for urethral reconstruction. Penile flaps are best characterized by the location/orientation of the harvested skin island, the pedicle origin, and the way in which the flap is incorporated into the urethra ${ }^{[17]}$. Flap techniques have also acquired the eponym of the surgeon who first described that technique. Details and success rates of penile skin flaps are discussed below and are summarized in Table 1.

\section{Penile anatomy}

Appropriate utilization of penile skin flaps depends on an understanding of the penile blood supply. The cross-sectional anatomy of the penis is shown in Figure 1. Penile skin flaps depend on the subcutaneous plexus traveling in the tunica dartos just superficial to Buck's fascia. This plexus is derived from axial penile arteries, which arise from the superficial and deep branches of the external pudendal artery [Figure 2].

\section{Types of penile skin flaps}

Penile skin flaps are described by anatomic classification. As described by Elliott and McAninch ${ }^{[17]}$, this classification should define the orientation of the harvested flap (longitudinal $v s$. transverse), the location where the skin island was derived (proximal vs. distal penile skin), the vascular supply (dorsal vs. ventrolateral pedicle), and how the flap is incorporated into the urethra (onlay $v s$. tube $v s$. combined tissue transfer). In addition to the anatomic description, the flap is also often described in the literature based on the eponym of the describing surgeon. For example, the longitudinal ventral penile skin flap with lateral pedicle placed as a ventral onlay is also referred to as the "Technique of Orandi" or "Orandi Flap"[27,28]. Further confusion can arise with modifications of classic descriptions, such as a tubularized "modified Orandi Flap" ${ }^{\text {[29] }}$. It is therefore important to adhere to the anatomic description described above.

Longitudinal ventral penile skin flap with lateral pedicle (Orandi flap) $)^{[28]}$

With the penis on stretch, a vertical, ventral penile shaft incision is made over the strictured area that corresponds to the approximate stricture length [Figure 3]. This incision should be carried lateral to the corpus spongiosum and will be the deep incision for flap harvest. On the contralateral side, a lateral urethrotomy is made until there is normal urethral mucosa is encountered at the proximal and distal aspects of the urethrotomy. A skin island is then dissected to match the urethrotomy defect. The superficial incision is then made and carried laterally to release the skin island and allow for suturing of the flap to the urethrotomy in a tension-free anastomosis [Figure 4].

Longitudinal ventral penile skin flap with ventral pedicle (Turner-Warwick flap) ${ }^{[30]}$

Similar to the Orandi ${ }^{[28]}$ technique, this is a skin island flap derived from ventral skin. The TurnerWarwick ${ }^{[30]}$ differs in that the pedicle is derived from bilateral ventrolateral arteries and used mostly in the bulbar urethra. Often the skin marking is made after perineal dissection and characterization of the bulbar urethral stricture. The deep plane of the skin island is developed distally, and the superficial layer is developed at the proximal flap apex. The island and pedicle are then raised and inverted through the scrotal tunnel and out the separate perineal incision to be incorporated into the bulbar urethra [Figure 5]. This technique has been described most in modern literature as part of augmented anastomotic urethroplasty. 
Table 1. Selection of published success rates for penile skin flaps in urethral reconstruction. Comments focus on unique features of the study included

\begin{tabular}{|c|c|c|c|c|c|}
\hline Technique & Authors & Year & Patients & Success & Comment \\
\hline \multirow{6}{*}{$\begin{array}{l}\text { Penile circular fasciocutaneous } \\
\text { flap urethroplasty (McAninch } \\
\text { Technique) }\end{array}$} & McAninch $^{[32]}$ & 1993 & 10 & $100 \%$ & Relatively short follow-up (14 m). Proof of concept \\
\hline & McAninch \& Morey ${ }^{[34]}$ & 1998 & 66 & $79 \%$ & Lower success with tubularized flap (58\%) \\
\hline & Alsikafi et al. ${ }^{[12]}$ & 2005 & 24 & $84 \%$ & $\begin{array}{l}\text { Forty-eight months follow-up. No significant } \\
\text { difference compared to buccal grafting (non- } \\
\text { randomized) }\end{array}$ \\
\hline & Dubey et al. ${ }^{[14]}$ & 2007 & 28 & $85.8 \%$ & $\begin{array}{l}\text { Randomized to skin flap vs. buccal mucosal graft. No } \\
\text { sig difference in recurrence. PROMs favored BMG }\end{array}$ \\
\hline & Whitson et al. ${ }^{[4]}$ & 2008 & 124 & $79 \%$ & $\begin{array}{l}\text { Success at } 1 \text { year }(95 \%) \text { declined over } 10 \text { years } \\
\text { follow-up ( } 79 \%) .5 \text { moking, prior hypospadias, and } \\
\text { long strictures }(7-10 \mathrm{~cm}) \text { predictive of failure }\end{array}$ \\
\hline & Kim et al. ${ }^{[36]}$ & 2014 & 29 & $69.9 \%$ & Included combined tissue transfer \\
\hline \multirow{5}{*}{$\begin{array}{l}\text { Longitudinal ventral penile skin } \\
\text { flap with lateral pedicle (Orandi } \\
\text { Technique) }\end{array}$} & Orandi ${ }^{[28]}$ & 1972 & 21 & $95 \%$ & Proof of concept \\
\hline & Goel et al. ${ }^{[27]}$ & 2015 & 10 & $80 \%$ & Four years follow-up. Small sample size \\
\hline & Hmida et al. ${ }^{[37]}$ & 2019 & 77 & $88 \%$ & $\begin{array}{l}\text { Younger age ( } 45) \text { than most studies. All recurrences } \\
\text { managed with DVIU }\end{array}$ \\
\hline & Ali et al. ${ }^{[38]}$ & 2019 & 42 & $85.7 \%$ & $\begin{array}{l}\text { Randomized to skin flap vs. buccal dorsal onlay. No } \\
\text { statistical differences. Short follow-up ( } 12 \text { months })\end{array}$ \\
\hline & El-Kassaby et al. ${ }^{[39]}$ & 2021 & 34 & $88 \%$ & Average length $<1 \mathrm{~cm}$ penile strictures \\
\hline $\begin{array}{l}\text { Transverse ventral penile skin flap } \\
\text { with ventral pedicle (Jordan } \\
\text { Technique) }\end{array}$ & Virasoro et al. $^{[40]}$ & 2007 & 35 & $83 \%$ & $\begin{array}{l}\text { Fossa novicularis strictures. Included lichen sclerosis } \\
\text { patients with lower success ( } 50 \%) \text {. Extensive follow- } \\
\text { up (10 years) }\end{array}$ \\
\hline
\end{tabular}

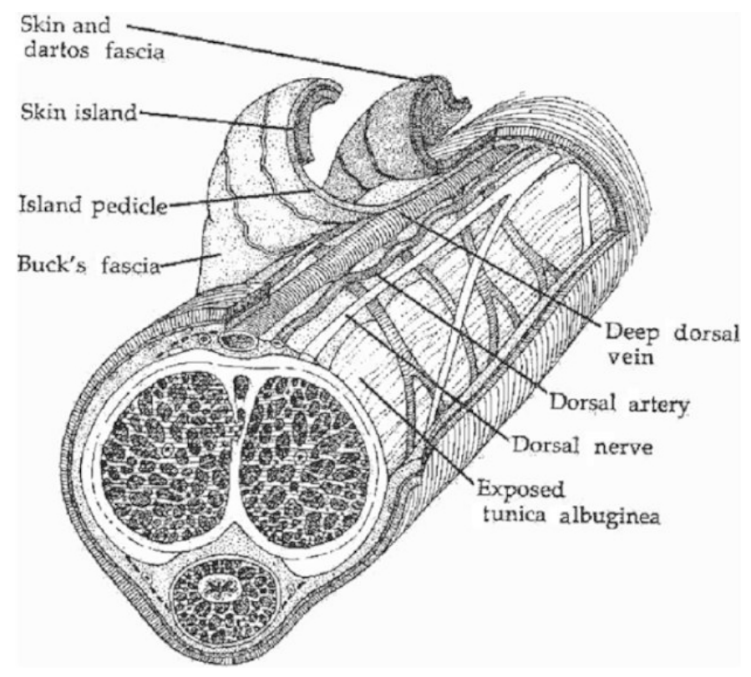

Figure 1. Fascial anatomy of the penis.

Ventral transverse penile island flap with ventral pedicle (Jordan flap) $)^{[31]}$

Similar to the Orandi ${ }^{[28]}$ and Turner-Warwick ${ }^{[30]}$ flaps, this technique isolates a distal penile skin flap from ventral penile skin. The pedicle is derived from bilateral ventrolateral arteries similar to the TurnerWarwick ${ }^{[30]}$. This technique is utilized in distal penile and fossa novicularis strictures and differs from other techniques with a broader pedicle and comparatively smaller skin island. Like other techniques, this is 


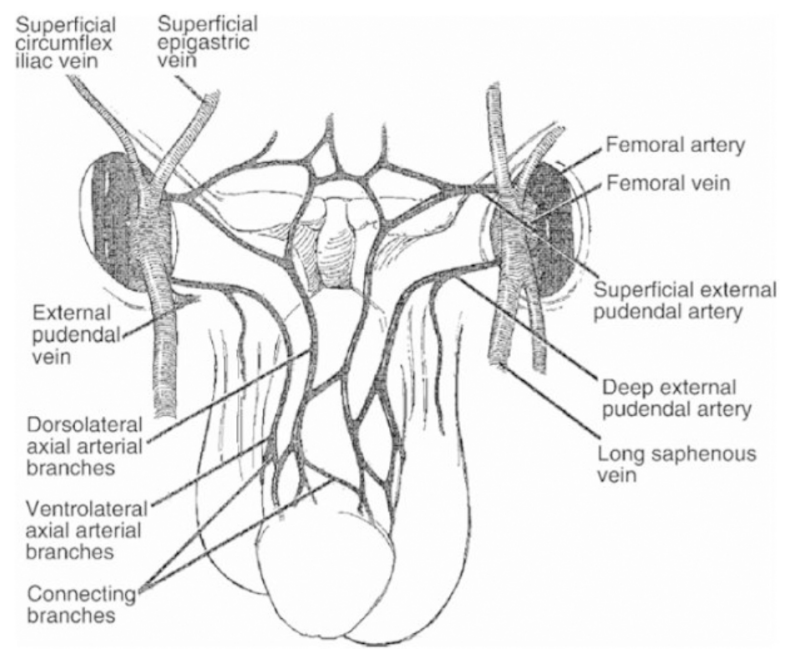

Figure 2. Artery supply and venous drainage of the penis.

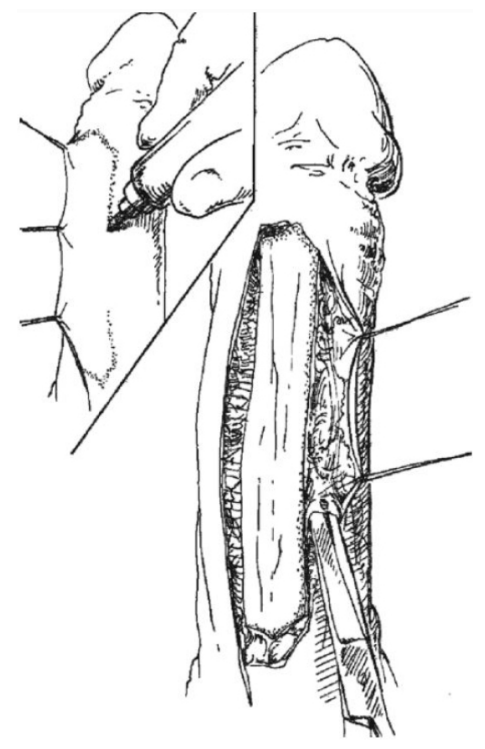

Figure 3. Technique of harvest of the Orandi flap.

anastomosed to the distal ventral urethra.

Transverse circular penile skin flap with primary dorsal pedicle (McAninch flap) ${ }^{[32]}$

With the penis on stretch, a circumferential skin flap (width $2-2.5 \mathrm{~cm}$ based on stricture caliber) is taken from the distal penile skin or inner prepuce [Figures 6 and 7]. First, the distal aspect of the flap should be dissected deep to the pedicle, leaving the pedicle with the proximal skin island. Next, the entire penile shaft should be degloved in this deep plane (superficial to bucks fascia). The proximal skin incision is then made superficial to the pedicle, creating a circumferential skin island that can be divided dorsally or ventrally to be rotated 90 degrees for urethral incorporation [Figures 8-10]. The flap is traditionally divided ventrally. Additional length can be generated in this technique by modifying the circumferential incision into a $\mathrm{Q}$ incision. 


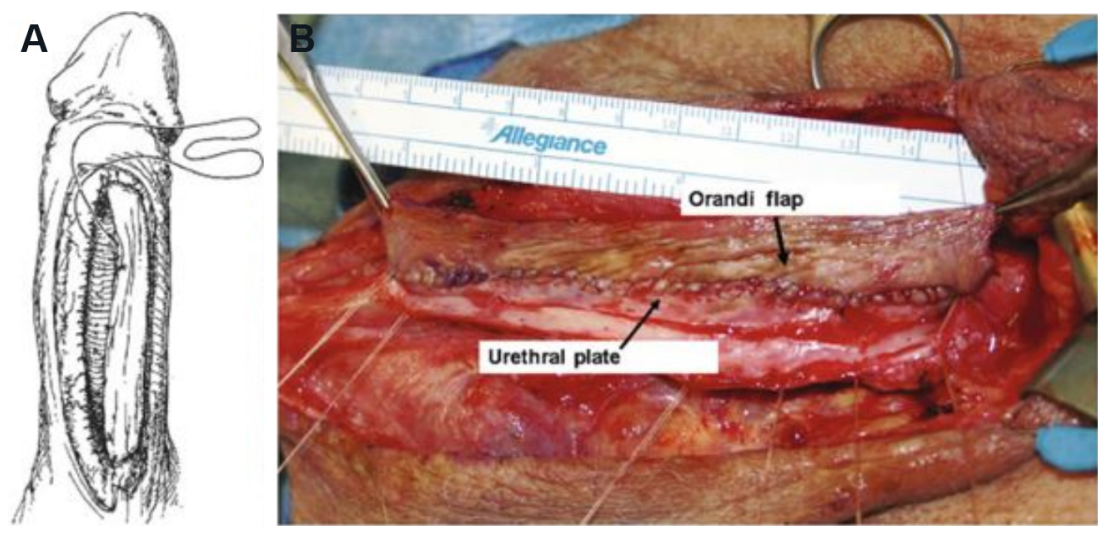

Figure 4. (A) Rotation and onlay anastomosis of the Orandi flap. (B) Orandi skin flap sewn to the urethral plate. Foley catheter then placed and contralateral side of the flap anastomosed.
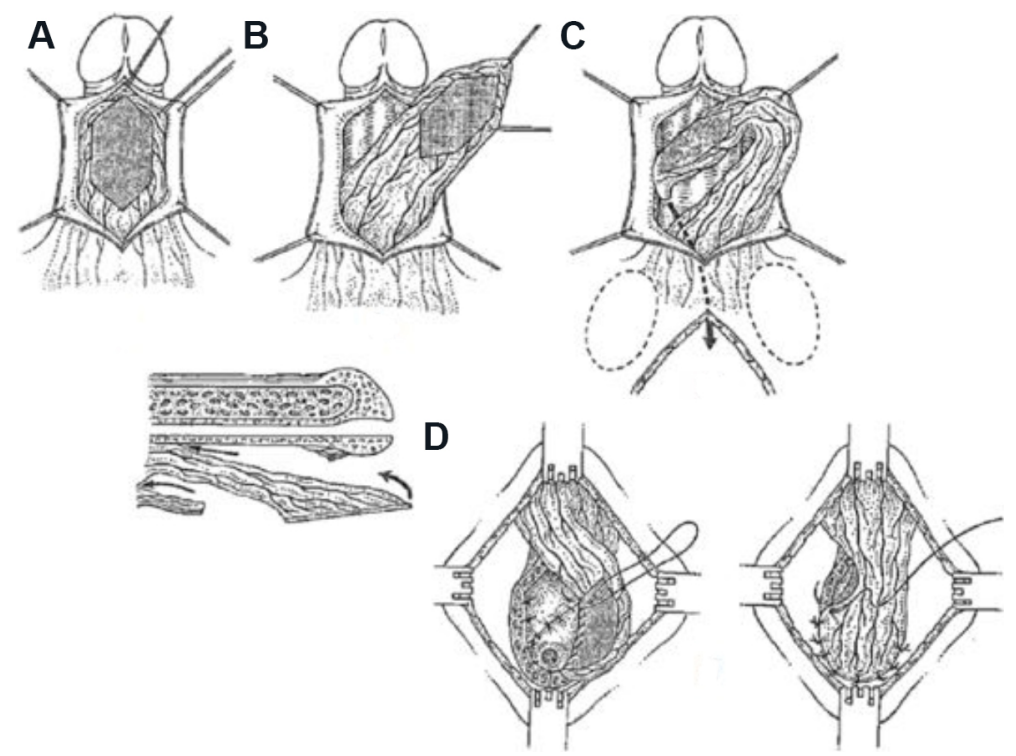

Figure 5. Technique of harvest of the Turner-Warwick flap (A-C) development of pedicles skin flap, (D) sewing the flap to the urethral plate.

\section{Single-stage vs. two-stage}

One of the benefits of penile skin flaps for urethral reconstruction is the adaptability to achieve adequate urethral patency in a single stage. For complex stricture disease, a two-stage repair may be required. In nonrandomized series, there is a lower re-stricture rate with two-stage procedures; however, there is a higher surgical revision rate ${ }^{[33]}$. Therefore, two-staged procedures should be considered in cases where single-staged options would have an unacceptable risk of recurrence. Specifically, American Urological Association guidelines recommend against single-stage tubularized graft urethroplasty due to high recurrence rate, and alternatives - including staged repair - should be pursued ${ }^{[3,35]}$.

\section{CONCLUSION}

Anterior urethral reconstruction requires a detailed understanding of patient disease, penile anatomy, and multiple operative approaches. Though some reviews have suggested improved patency rates with BMG compared to penile skin flaps ${ }^{[8]}$, many of these studies have shorter follow-up for BMG, and multiple 


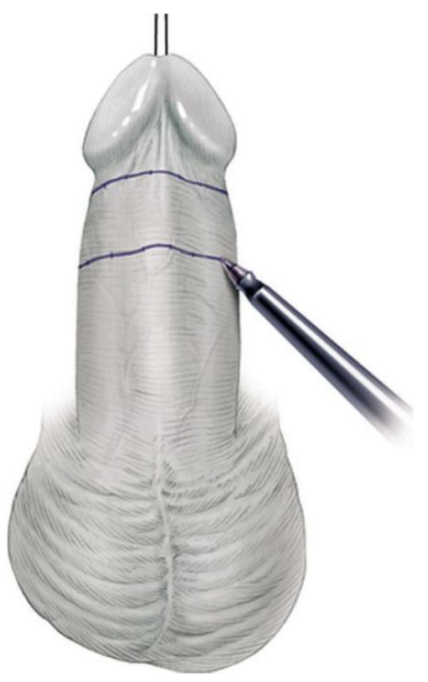

Figure 6. Skin markings for flap harvest.

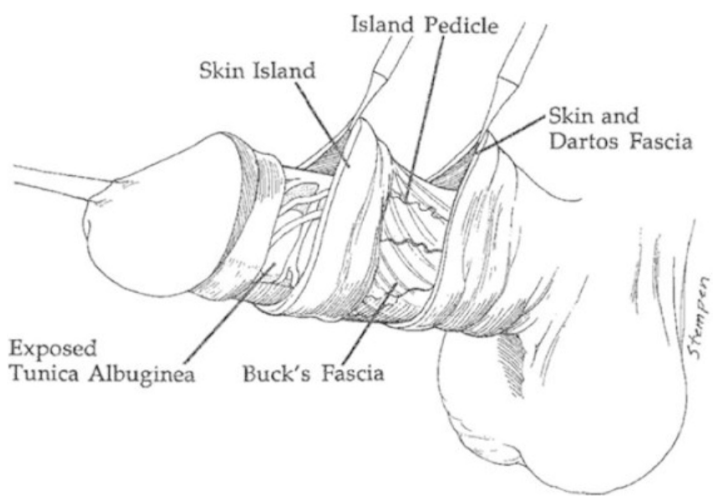

Figure 7. Technique of harvest of the McAninch flap.

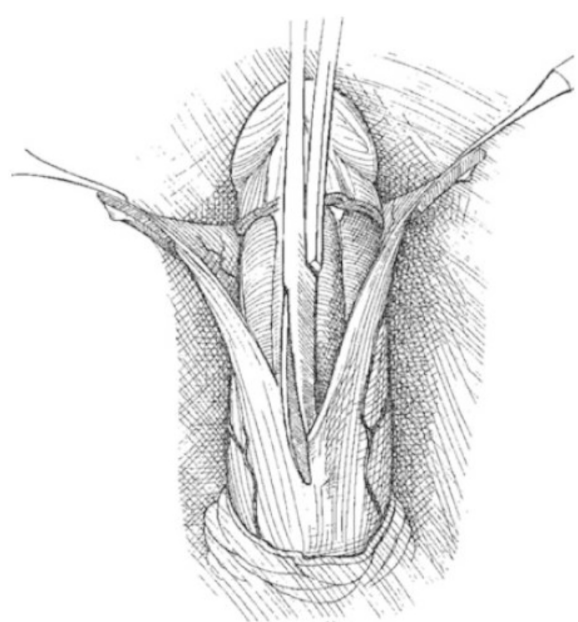

Figure 8. Ventral division of the skin island and pedicle in the midline. 


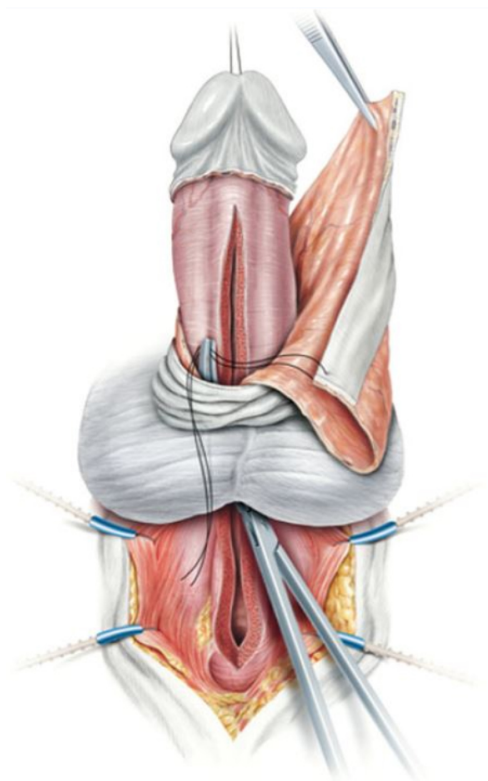

Figure 9. Ninety-degree flap rotation and ventral transposition.

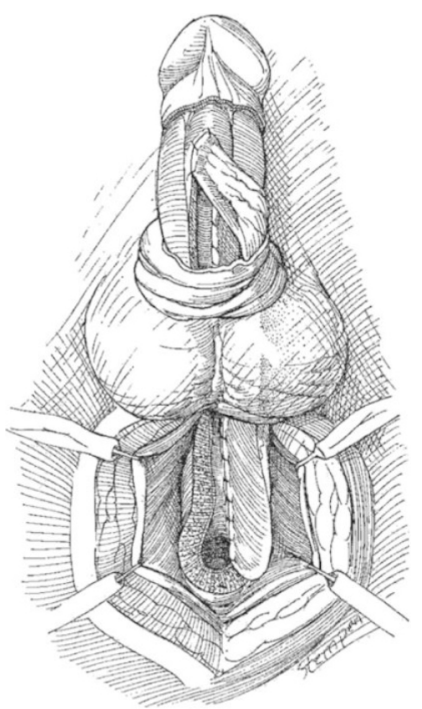

Figure 10. Onlay anastomosis of the McAninch flap.

randomized studies have not shown a benefit of one technique over another. Thus, while flaps have fallen out of favor as a mainstream reconstructive option in favor of BMG, penile skin flaps continue to play an important role in urethral reconstruction particularly in the penile urethra in appropriately selected patients.

\section{DECLARATIONS}

\section{Authors' contributions}

Manuscript draft, literature review: Shaw NM

Manuscript draft, editorial corrections: Amend G 
Manuscript draft, conception, and design: Breyer BN

\section{Availability of data and materials}

Data not included in the review can be made available on request.

\section{Financial support and sponsorship}

None.

\section{Conflicts of interest}

All authors declared that there are no conflicts of interest.

\section{Ethical approval and consent to participate}

Not applicable.

\section{Consent for publication}

Figures reprinted with written permission from Spring Nature. Otherwise not applicable.

\section{Copyright}

(c) The Author(s) 2021.

\section{REFERENCES}

1. Faris SF, Myers JB, Voelzke BB, et al; Trauma and Urologic Reconstruction Network of Surgeons (TURNS). Assessment of the male urethral reconstruction learning curve. Urology 2016;89:137-42. DOI PubMed PMC

2. Wisenbaugh ES, Gelman J. The use of flaps and grafts in the treatment of urethral stricture disease. Adv Urol 2015;2015:979868. DOI PubMed PMC

3. Andrich DE, Mundy AR. What is the best technique for urethroplasty? Eur Urol 2008;54:1031-41. DOI PubMed

4. Whitson JM, McAninch JW, Elliott SP, Alsikafi NF. Long-term efficacy of distal penile circular fasciocutaneous flaps for single stage reconstruction of complex anterior urethral stricture disease. J Urol 2008;179:2259-64. DOI PubMed

5. Venn SN, Mundy AR. Urethroplasty for balanitis xerotica obliterans. Br J Urol 1998;81:735-7. DOI PubMed

6. Depasquale I, Park AJ, Bracka A. The treatment of balanitis xerotica obliterans. BJU Int 2000;86:459-65. DOI PubMed

7. Belsante MJ, Selph JP, Peterson AC. The contemporary management of urethral strictures in men resulting from lichen sclerosus. Transl Androl Urol 2015;4:22-8. DOI PubMed PMC

8. Lumen N, Oosterlinck W, Hoebeke P. Urethral reconstruction using buccal mucosa or penile skin grafts: systematic review and metaanalysis. Urol Int 2012;89:387-94. DOI PubMed

9. Gallegos MA, Santucci RA. Advances in urethral stricture management. F1000Res 2016;5:2913. DOI PubMed PMC

10. Wessells H, Mcaninch JW. Use of free grafts in urethral stricture reconstruction. J Urol 1996;155:1912-5. PubMed

11. Bhargava S, Chapple CR. Buccal mucosal urethroplasty: is it the new gold standard? BJU Int 2004;93:1191-3. DOI PubMed

12. Alsikafi NF, Eisenberg M, Mcaninch JW. 317: Long-term outcomes of penile skin graft versus buccal mucosal graft for substitution urethroplasty of the anterior urethra. J Urol 2005;173:87-8. DOI

13. Breyer BN, McAninch JW, Whitson JM, et al. Multivariate analysis of risk factors for long-term urethroplasty outcome. $J$ Urol 2010;183:613-7. DOI PubMed

14. Dubey D, Vijjan V, Kapoor R, et al. Dorsal onlay buccal mucosa versus penile skin flap urethroplasty for anterior urethral strictures: results from a randomized prospective trial. J Urol 2007;178:2466-9. DOI PubMed

15. Chapman DW, Cotter K, Johnsen NV, et al. Nontransecting techniques reduce sexual dysfunction after anastomotic bulbar urethroplasty: results of a multi-institutional comparative analysis. J Urol 2019;201:364-70. DOI PubMed

16. Blaschko SD, Sanford MT, Cinman NM, McAninch JW, Breyer BN. De novo erectile dysfunction after anterior urethroplasty: a systematic review and meta-analysis. BJU Int 2013;112:655-63. DOI PubMed PMC

17. Elliott SP, Mcaninch JW. Penile skin flaps for urethral reconstruction. In: Brandes SB, editor. Urethral reconstructive surgery. Totowa: Humana Press; 2008. p. 153-64.

18. Gil-Vernet J, Arango O, Gil-Vernet A, Gil-Vernet JJ, Gelabert-Mas A. A new biaxial epilated scrotal flap for reconstructive urethral surgery. J Urol 1997;158:412-20. PubMed

19. Carrera A, Gil-Vernet A, Forcada P, Morro R, Llusa M, Arango O. Arteries of the scrotum: a microvascular study and its application to urethral reconstruction with scrotal flaps. BJU Int 2009;103:820-4. DOI PubMed

20. Gil-Vernet A, Arango O, Gil-Vernet JJ, Gelabert-Mas A, Gil-Vernet J. Scrotal flap epilation in urethroplasty: concepts and technique. J Urol 1995;154:1723-6. PubMed

21. Provet JA, Surya BV, Grunberger I, Johanson K, Brown J. Scrotal island flap urethroplasty in the management of bulbar urethral 
strictures. J Urol 1989;142:1455-7. DOI PubMed

22. Yachia D. A New, One-Stage Pedicled scrotal skin graft urethroplasty. J Urol 1986;136:589-92. DOI PubMed

23. Blandy J. Two stage scrotal flap urethroplasty. Ann Urol (Paris) 1993;27:213-8; discussion 219. PubMed

24. Blandy JP, Singh M, Notley RG, Tresidder GC. The results and complications of scrotal-flap urethroplasty for stricture. Br J Urol 1971;43:52-7. DOI PubMed

25. Zinman L. Muscular, myocutaneous, and fasciocutaneous flaps in complex urethral reconstruction. Urol Clin North Am 2002;29:44366. DOI PubMed

26. Nikolavsky D. Prelaminated gracilis flap with buccal mucosal graft for salvage of devastated urethra. Case Rep Urol 2015;2015:490518. DOI PubMed PMC

27. Goel A, Kumar M, Singh M. Orandi flap for penile urethral stricture: polishing the gold standard. Can Urol Assoc J 2015;9:E160-3. DOI PubMed PMC

28. Orandi A. One-stage urethroplasty: 4-year followup. J Urol 1972;107:977-80. DOI PubMed

29. Heo JW, Hong WT, Kim YH, Yang CE, Kim J, Kim SW. Urethroplasty of extensive penile urethral strictures with a longitudinal ventral tubed flap of penile skin (modified Orandi urethroplasty): 20 years of follow-up of two cases. Arch Plast Surg 2020;47:613-8. DOI PubMed PMC

30. Turner-Warwick R. Principles of urethral reconstruction. Reconstr Urol 1993;2:609-42. DOI PubMed

31. Jordan GH. Reconstruction of the fossa navicularis. J Urol 1987;138:102-4. DOI PubMed

32. Mcaninch JW. Reconstruction of extensive urethral strictures: circular fasciocutaneous penile flap. J Urol 1993;149:488-91. DOI PubMed

33. Andrich DE, Greenwell TJ, Mundy AR. The problems of penile urethroplasty with particular reference to 2-stage reconstructions. $J$ Urol 2003;170:87-9. DOI PubMed

34. McAninch JW, Morey AF. Penile circular fasciocutaneous skin flap in 1-stage reconstruction of complex anterior urethral strictures. $J$ Urol 1998;159:1209-13. PubMed

35. Wessells H, Angermeier KW, Elliott S, et al. Male urethral stricture: American Urological Association guideline. J Urol 2017;197:182-90. DOI PubMed

36. Kim KR, Suh JG, Paick JS, Kim SW. Surgical outcome of urethroplasty using penile circular fasciocutaneous flap for anterior urethral stricture. World J Mens Health 2014;32:87-92. DOI PubMed PMC

37. Hmida W, Othmen MB, Bako A, Jaidane M, Mosbah F. Penile skin flap: a versatile substitute for anterior urethral stricture. Int Braz J Urol 2019;45:1057-63. DOI PubMed PMC

38. Ali AI, Hamid AA, Abdel-Rassoul MA, et al. Buccal mucosal graft versus penile skin flap urethroplasty for long segment penile urethral stricture: a prospective randomized study. Cent European J Urol 2019;72:191-7. DOI PubMed PMC

39. El-kassaby AW, Saber Khalaf M, Reyad AM. Management of men with ultra-short penile urethral stricture using augmented anastomotic penile skin flap urethroplasty; a retrospective analysis. Afr J Urol 2021;27:33. DOI

40. Virasoro R, Eltahawy EA, Jordan GH. Long-term follow-up for reconstruction of strictures of the fossa navicularis with a single technique. BJU Int 2007;100:1143-5. DOI PubMed 